\title{
Direct observation of the metamorphism of silicon oxide grains
}

\author{
K. Kamitsuji, S. Ueno, H. Suzuki, Y. Kimura, T. Sato, T. Tanigaki, O. Kido, M. Kurumada, and C. Kaito \\ Department of Nanophysics in Frontier Projects, Ritsumeikan University, Kusatsu-shi, Shiga 525-8577, Japan \\ e-mail: rp007988@se.ritsumei.ac.jp \\ Received 19 September 2003 / Accepted 23 March 2004
}

\begin{abstract}
Experimental studies on the metamorphism of $\mathrm{SiO}_{x}$ grains under heating at $10^{-6} \mathrm{~Pa}$ have been conducted using a high-resolution transmission electron microscope. Si crystallites were predominantly grown at 500 to $700{ }^{\circ} \mathrm{C}$ in $\mathrm{SiO}_{x}$ grains. The Si crystallites disappeared at $800{ }^{\circ} \mathrm{C}$ and evaporated as the $\mathrm{SiO}$ phase.
\end{abstract}

Key words. astrochemistry - acceleration of particles - method: laboratory - Stars: AGB and post-AGB stars: circumstellar matter - ISM: dust, extinction

\section{Introduction}

Dust formation in oxygen-rich ejecta is based on excess oxygen and the elements $\mathrm{Mg}, \mathrm{Fe}, \mathrm{Si}$ and $\mathrm{Al}$. Therefore we expect the formation of silicates and other metal oxides. This expectation is confirmed by spectroscopic observations of circumstellar envelopes around M-type giants (Dorschner \& Henning 1995; Henning et al. 1997; Sandford 1996). The formation of silicates should start with the formation of $\mathrm{SiO}_{x}$ clusters. Laboratory experiments with $\mathrm{H}_{2}-\mathrm{SiO}-\mathrm{FeO}-\mathrm{SiO}$, and $\mathrm{H}_{2}-\mathrm{Mg}-\mathrm{SiO}$ systems suggest the formation of amorphous unequilibrated solids with non-stoichiometric element ratios (Nuth 1996). The detection by ISO of a crystalline silicate component in the spectra of evolved stars has awaited a detailed explanation (Waters et al. 1996). We previously demonstrated the production of crystalline forsterite grains due to the coalescence and growth of $\mathrm{Mg}$ and $\mathrm{SiO}$ smoke grains (Kaito et al. 2003). The High-Resolution Transmission Electron Microscope (HRTEM) shows that the $\mathrm{SiO}$ film produced by vacuum condensation following the evaporation of $\mathrm{SiO}$ powder is composed of a mixture of silicon and $\alpha$-cristobalite nanocrystallites (Kaito \& Shimizu 1984). The shift of infrared peaks that occurs when the film is heated in air has been understood as a phase transition of $\mathrm{SiO}_{2}$ into an amorphous state with accompanying oxidation of silicon metal nanocrystallites (Morioka et al. 1998). The initial film was completely changed into a quartz film upon heating at $500{ }^{\circ} \mathrm{C}$. Similar experiments using $\mathrm{SiO}$ grains prepared by the evaporation of $\mathrm{SiO}$ powder in an $\mathrm{Ar}$ gas atmosphere (gas evaporation technique) yield the same results for the film (Morioka et al. 1997). The metamorphic alteration in the amorphous state can be duplicated in the solid state in air.

Since the estimated pressure of the solar nebula at 2-3 AU is low (Nagahara et al. 1994), experiments on metamorphism in a vacuum are important for comparison with condensation, evaporation, melting and crystallization in the primitive solar nebula (Nuth 1996; Mysen \& Kushiro 1988). We can directly observe phenomena involving any grains at high temperature by using the special heating holder attached to a transmission electron microscope (TEM). In a recent experiment, we succeeded in observing new phenomena such as the temperature dependence of dissolution and the precipitation of carbon on SiC grains using HRTEM (Atou et al. 2003; Kimura et al. 2003).

In this paper, we report direct observations of the heating of $\mathrm{SiO}_{x}$ grains up to $1000{ }^{\circ} \mathrm{C}$ in vacuum at $10^{-6} \mathrm{~Pa}$. The dynamic behavior of the grains was recorded on video tape.

\section{The experiments}

$\mathrm{SiO}_{x}$ grains were produced by evaporating commercial $\mathrm{SiO}$ powder in $\mathrm{Ar}$ gas at $10 \mathrm{kPa}$ (Morioka et al. 1997). Yellowish grains of $\mathrm{SiO}_{x}$ (including $\mathrm{Si}_{2} \mathrm{O}_{3}$ ) were collected on glass plates (Phillips 1971). The collected samples were placed in the sample holder used for in situ observation of the heating process (Kimura et al. 2003).

Metamorphism of the specimen was directly observed using a Hitachi H-9000NAR HRTEM with a special heating holder, which can be heated to approximately $1500{ }^{\circ} \mathrm{C}$ (Kimura et al. 2000). The images were magnified by a factor of twenty using a television system. The images were recorded on video tape.

\section{Results and discussion}

As-grown $\mathrm{SiO}$ grains collected on a standard electron microscopic grid are shown in Fig. 1a. Spherical particles of $30 \mathrm{~nm}$ in diameter were produced. As indicated by arrows, small black dots $\sim 2 \mathrm{~nm}$ in size can be seen in each particle. Electron diffraction (ED) patterns showed that the grains produced were amorphous.

The HRTEM image of part of a grain is shown in Fig. $1 b$. As indicated by arrows, lattice fringes can be seen in the range 


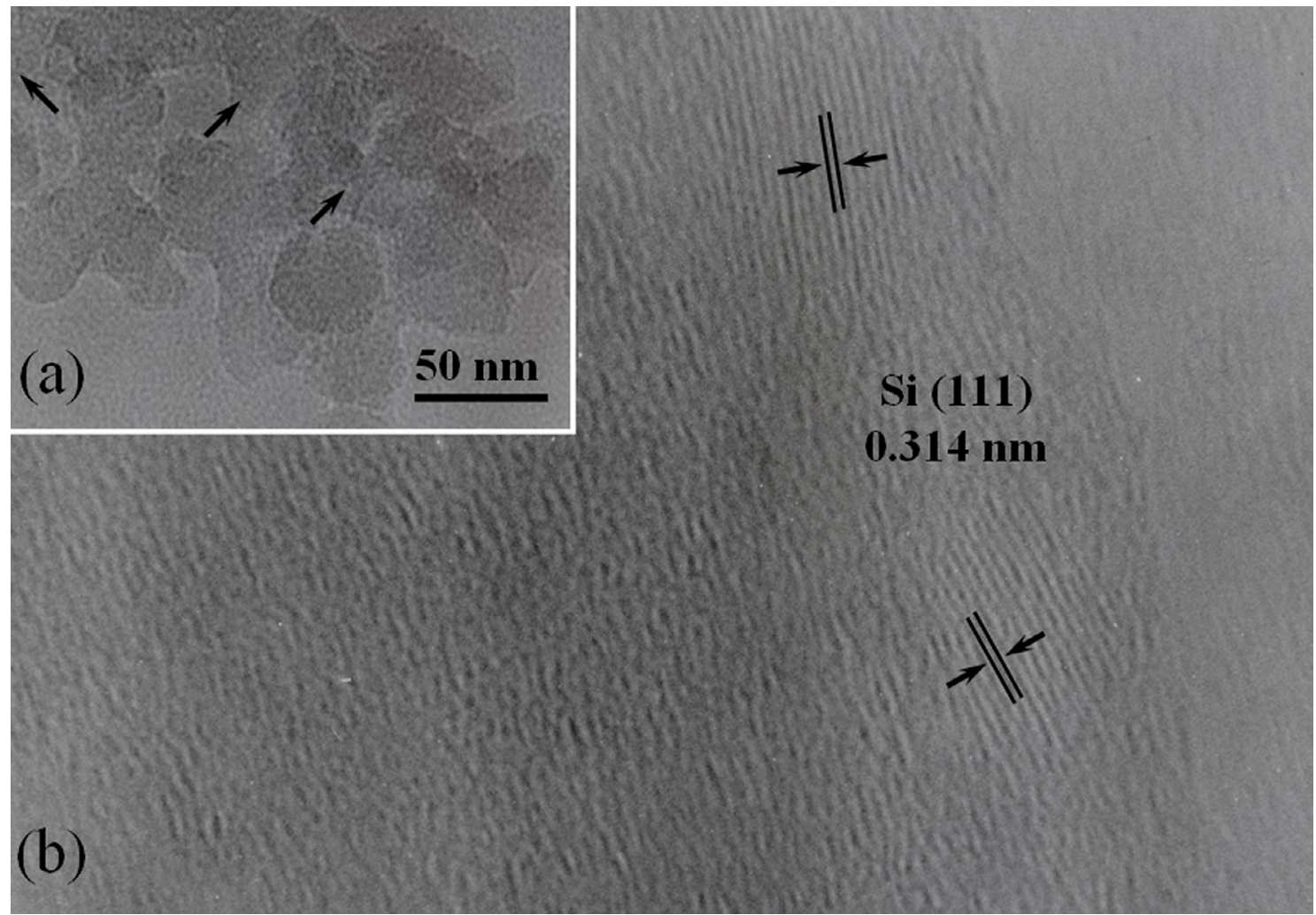

Fig. 1. TEM image of a SiO grain. Si crystallites can be seen as black dots as indicated by arrows in the low-magnification image. These black dots correspond to Si crystallites as seen in the high-resolution image in this photograph.

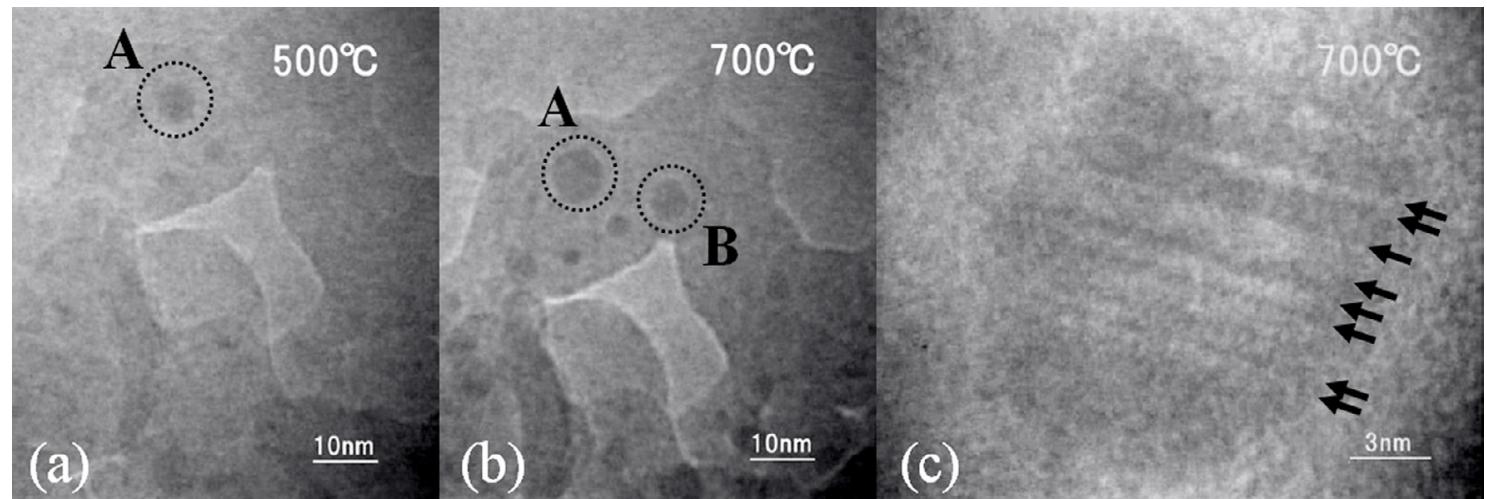

Fig. 2. In situ image of heated grains at a) 500 and b) $700{ }^{\circ} \mathrm{C}$. The black region is due to the growth of silicon crystallites between 500 to $700{ }^{\circ} \mathrm{C}$. Typical stacking faults of $\mathrm{Si}$ metal in an $\mathrm{SiO}$ particle are shown in $\mathbf{c}$ ).

of $2 \mathrm{~nm}$ and thus the black dots are identified as silicon metal crystallites. The IR spectrum of these particles showed the characteristic $\beta$-cristobalite spectrum (Morioka et al. 1997). Therefore, the $\mathrm{SiO}$ grains we started with were composed of silicon metal and $\beta$-cristobalite $\left(\mathrm{SiO}_{2}\right)$ as described in a previous report on the basis of spectroscopy (Morioka et al. 1997). In the present HRTEM observation of the grains, the existence of metallic silicon was also confirmed as was the film (Kaito \& Shimizu 1984).

\subsection{Metamorphism of $\mathrm{SiO}_{x}$ grains in a vacuum}

When heating the $\mathrm{SiO}_{x}$ sample at $450{ }^{\circ} \mathrm{C}$ in a vacuum, no significant structural alterations were observed. Upon heating at 500 to $700{ }^{\circ} \mathrm{C}$, silicon crystallites, indicated in Fig. 1b, grew in the $\mathrm{SiO}_{x}$ grains. Figures $2 \mathrm{a}$ and $2 \mathrm{~b}$ show the TEM images printed from the video image of $\mathrm{SiO}_{x}$ particles at the same place at 500 and $700{ }^{\circ} \mathrm{C}$. The area of black contrast indicated by circle A in Fig. 2b was larger than that in Fig. 4a. A new, large, black-contrast area was seen in circle B. In another region, the black contrast area became larger upon heating at $700{ }^{\circ} \mathrm{C}$. Silicon metal crystallites became predominant at $700{ }^{\circ} \mathrm{C}$. The enlarged image in Fig. 2c shows stacking faults in a grown silicon crystal. This silicon crystal growth suggests that $\mathrm{Si}$ atoms diffuse in $\mathrm{SiO}_{x}$ between 500 to $700{ }^{\circ} \mathrm{C}$.

Figure 3 shows the ED patterns from grains heated to 500, 750 and $1000{ }^{\circ} \mathrm{C}$. The haloes become sharp in spite of the 


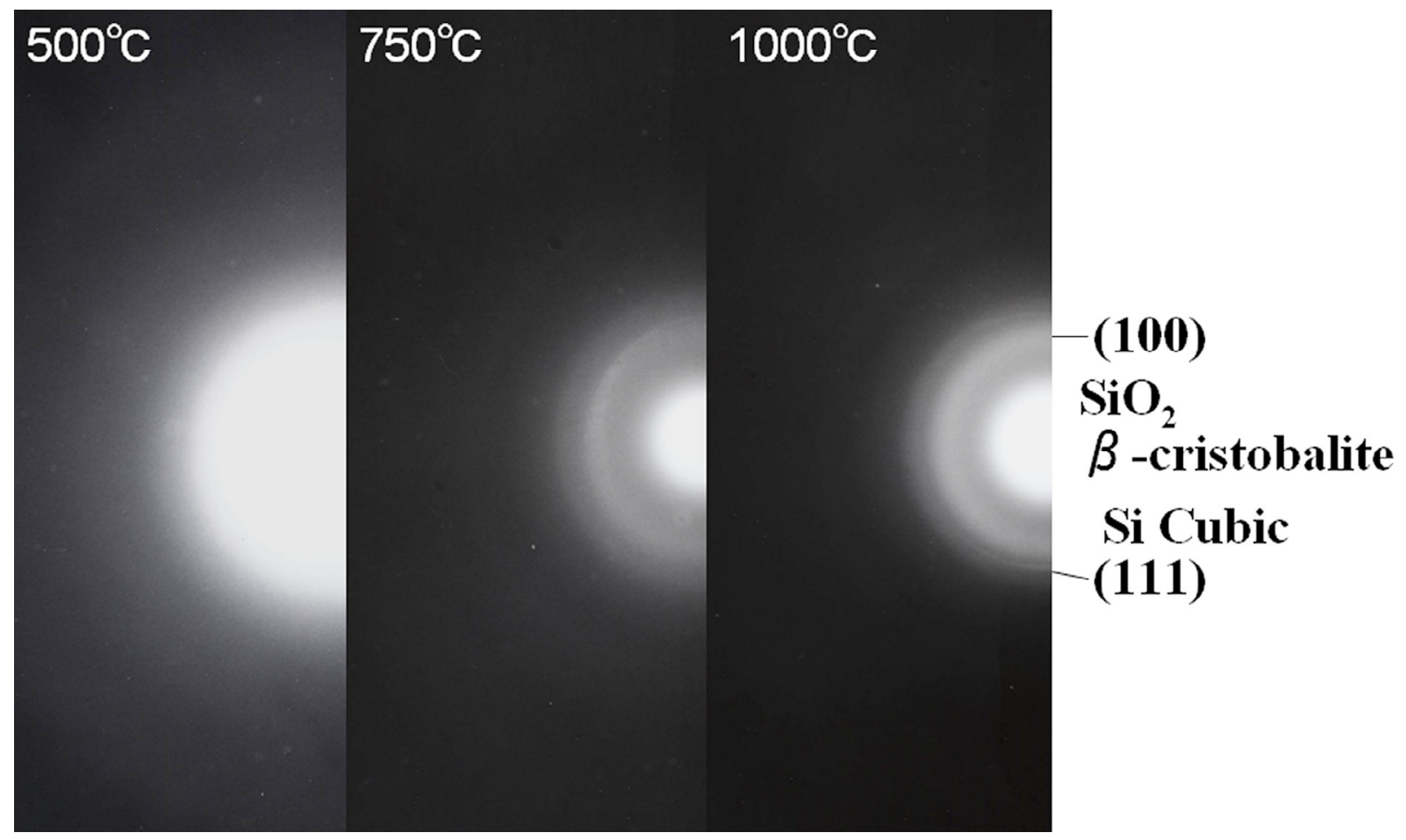

Fig. 3. Typical ED patterns in $\mathrm{SiO}$ grains at 500,750 and $1000^{\circ} \mathrm{C}$ respectively. Diffuse rings became sharper in spite of the high temperature. The diffraction rings can be identified as those of $\mathrm{Si}$ and $\beta$-cristobalite.
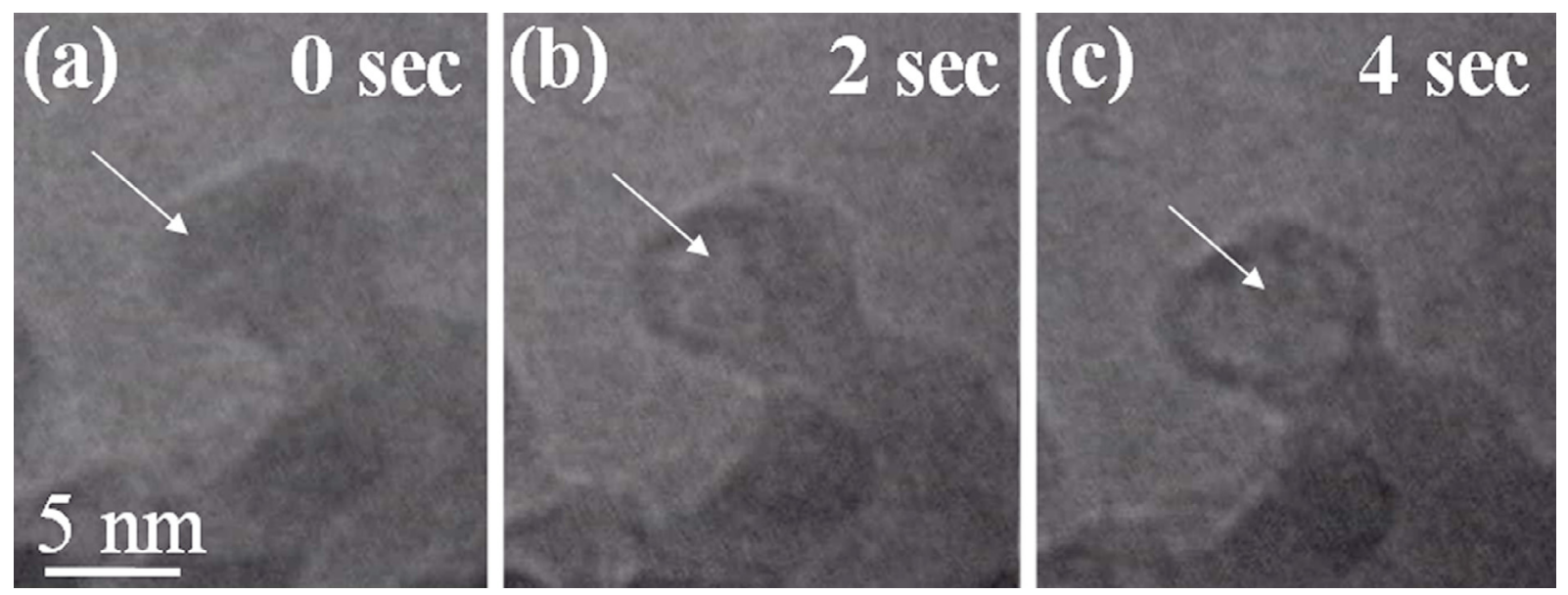

Fig. 4. Evaporation of an $\mathrm{SiO}$ particle heated at $900^{\circ} \mathrm{C}$. The $\mathrm{Si}$ crystallite seen in Fig. 4 disappeared and evaporation began. The $\mathrm{SiO}$ phase was formed and began to sublime. Figures $4 \mathrm{a}-\mathrm{c}$ show the same particles. The time intervals from a) to b) and a) to c) are 2 and $4 \mathrm{~s}$, respectively.

heating. It also becomes evident from the ED pattern that $\mathrm{Si}$ and $\mathrm{SiO}_{2}$ crystallites grow in $\mathrm{SiO}_{x}$ grains.

Upon heating to $900{ }^{\circ} \mathrm{C}$, the silicon metal crystals seen as the black contrast areas became smaller and finally disappeared. As shown in Figs. 4a-c, parts of the grains indicated by arrows gradually evaporated. The evaporation rate was $\sim 3 \mathrm{~nm} / \mathrm{s}$, as estimated from the video images at $900{ }^{\circ} \mathrm{C}$.

The solid grains and films of $\mathrm{SiO}_{x}$ were composed of a mixture of $\mathrm{SiO}_{2}$ and $\mathrm{Si}$. Up to $700{ }^{\circ} \mathrm{C}$ the silicon crystallites grew, and they disappeared when evaporation occurred above $900{ }^{\circ} \mathrm{C}$. This shows that $\mathrm{SiO}$ component grains form at high temperature in agreement with the phase diagram of the $\mathrm{Si}_{-} \mathrm{SiO}_{2}$ system (Sosmamn 1995). However, the present $\mathrm{SiO}$ formation temperature is about $75 \%$ lower than bulk data would indicate. These effects are similar to those observed in grain formation by coalescence in the $\mathrm{Mg}-\mathrm{SiO}$ smoke system at low temperature (Kaito et al. 2003). Since $\mathrm{SiO}$ smoke can be obtained by evaporation of $\mathrm{SiO}$ powder from a tungsten boat by heating above $1400{ }^{\circ} \mathrm{C}$, the evaporation seen in Fig. 4 occurs at temperatures $\sim 60-70 \%$ lower.

When the grains were cooled down, silicon metal crystal growth could again be seen to occur predominantly in the range of 750 to $500^{\circ} \mathrm{C}$. A typical TEM image and corresponding ED pattern of the specimens cooled to $700{ }^{\circ} \mathrm{C}$ are shown in Fig. 5. The diffraction rings can be interpreted as showing the existence of silicon metal crystals of about $10 \mathrm{~nm}$ in 


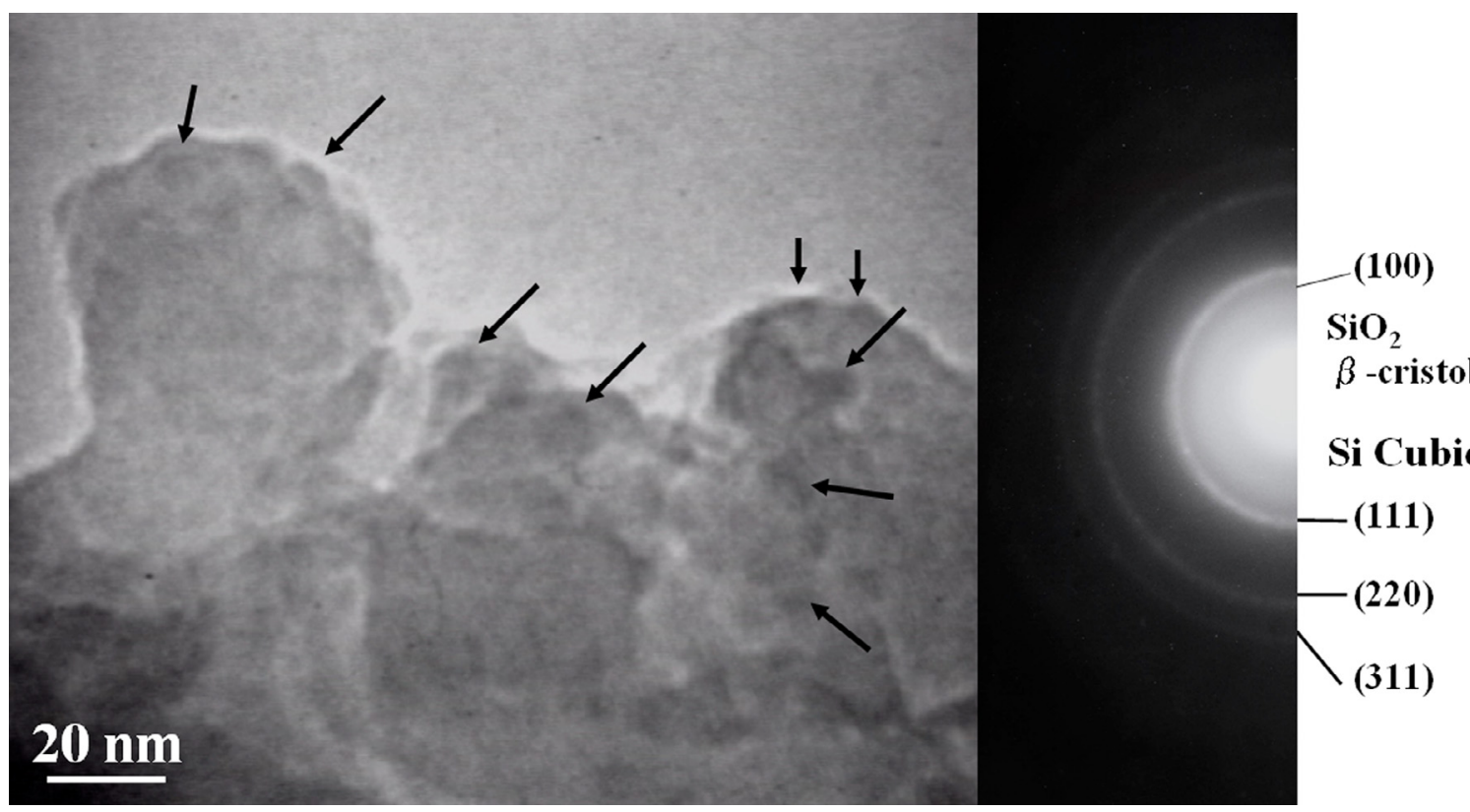

Fig. 5. When the $\mathrm{SiO}$ grains are cooled to $700{ }^{\circ} \mathrm{C}$, the appearance of silicon crystallites was seen as indicated by arrows. This is also consistent with the result of heating the specimen as indicated in Fig. 2. The ED pattern clearly shows the growth of silicon crystallites.

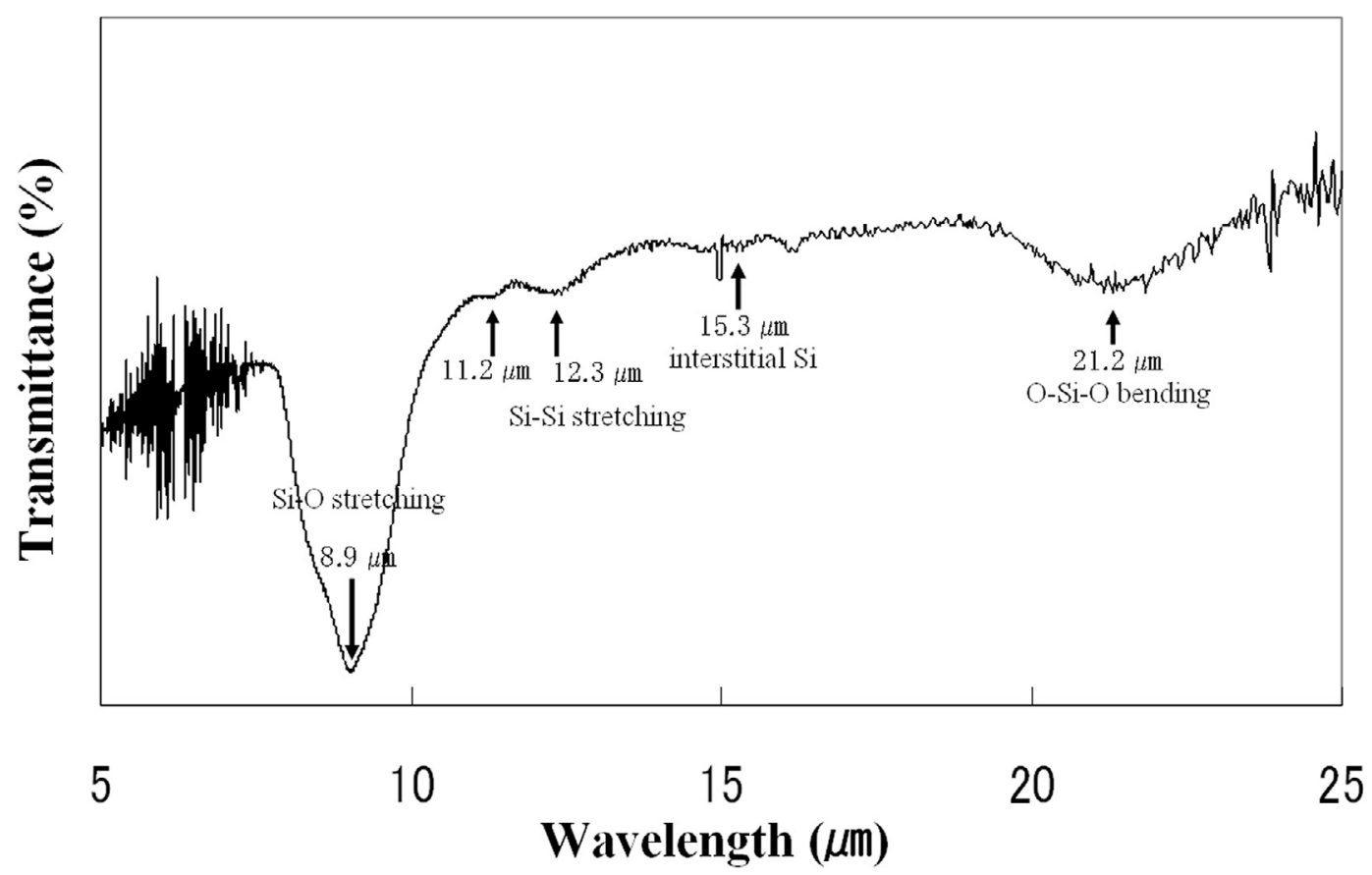

Fig. 6. IR spectrum after heating the $\mathrm{SiO}$ specimen at $750{ }^{\circ} \mathrm{C}$. Characteristic $\mathrm{Si}-\mathrm{O}$ stretching at 11.2 and $12.3 \mu \mathrm{m}$ due to $\beta$-cristobalite can be clearly seen.

diameter. IR spectra before and after heat treatment in vacuum did not change, since silicon metal is not IR active. Figure 6 shows the IR spectra of the $\mathrm{SiO}_{x}$ grains after heat treatment at $750{ }^{\circ} \mathrm{C}$. The characteristic absorption indicates the existence of $\beta$-cristobalite (Morioka 1997).

The $\mathrm{SiO}$ phase can be obtained by heating $\mathrm{SiO}_{x}$ grains above $800{ }^{\circ} \mathrm{C}$ in a vacuum. The selective growth of silicon nanocrystals took place between 500 and $750^{\circ} \mathrm{C}$. The as-grown $\mathrm{SiO}_{x}$ grains produced by gas evaporation were composed of silicon metal and $\beta$-cristobalite in contrast to the as-deposited film, which was composed of silicon and $\alpha$-cristobalite (Kaito \& Shimizu 1984; Morioka et al. 1998). This is due to the difference in condensation from the gas to solid, i.e., $\mathrm{SiO}_{x}$ grains in this experiment were condensed near the evaporation source and kept at about $500{ }^{\circ} \mathrm{C}$ at $5 \mathrm{~nm}$ above the evaporation source (Kaito \& Fujita 1986); therefore, silicon crystallites were grown and the high-temperature $\beta$-phase was retained after cooling below $500{ }^{\circ} \mathrm{C}$. In the case of film growth, the more 


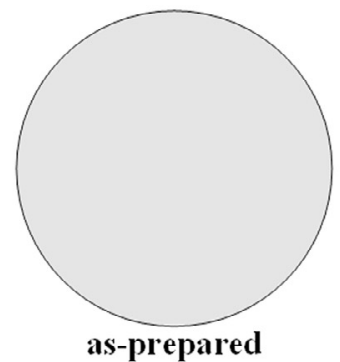

$\mathrm{SiO}$ grain, a composite of $\mathrm{Si}$ and $\mathrm{SiO}_{2}$ microcrystallites.

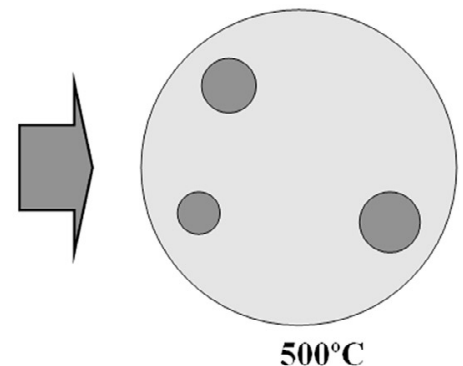

$500^{\circ} \mathrm{C}$

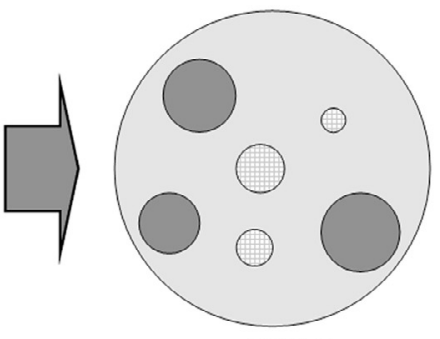

$700^{\circ} \mathrm{C}$

Si microcrystallites start growing. $\mathrm{SiO}_{2}$ microcrystallites start growing, they are also identified in the ED

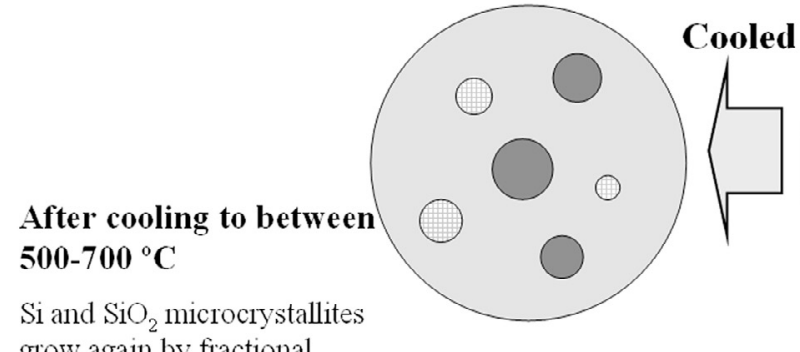
grow again by fractional decomposition of $\mathrm{SiO}$ into $\mathrm{Si}$ metal and $\mathrm{SiO}_{2}$
:Si microcrystallite

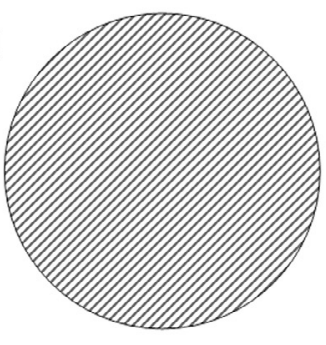
pattern.

\section{$: \mathrm{SiO}_{2}$ microcrystallite}

Fig. 7. Schematic picture of the decomposition process of a particle.

rapid condensation from the vapor phase onto the relatively cool substrate is dominant (Morioka et al. 1998); therefore, a metastable phase is produced (Rietmeijer et al. 1999).

\section{Conclusions}

Partial evaporation of $\mathrm{SiO}_{x}$ grains, composed of $\mathrm{Si}$ and $\mathrm{SiO}_{2}$ crystallites, is due to the formation of the $\mathrm{SiO}$ phase during vacuum heating. The main changes in the $\mathrm{SiO}$ grains caused by heating are summarized schematically in Fig. 7.

Since silicate dust has been detected in different objects, such as in the circumstellar envelopes of evolved stars, planetary nebula, young stellar objects, proto-planetary disks and comets, it is likely that many grains have undergone some degree of metamorphism since their formation (Nuth 1996). In the present experiment on $\mathrm{SiO}_{x}$ grains, it is evident that the formation of $\mathrm{SiO}_{x}$ grains and the evaporation of the $\mathrm{SiO}$ phase took place at about $70 \%$ lower temperature than one would expect from the bulk data. Though from the thermodynamic data the vapor pressure of $\mathrm{SiO}$ at $900{ }^{\circ} \mathrm{C}$ was estimated to be of the order of $10^{-3}$ Torr (Nuth \& Donn 1982), the contribution of surface energy can accelerate the evaporation of grains. A similar effect can be seen in the process of coalescence and growth in the smoke (Kaito 1985). The crystalline forsterite grain formation by coalescence between $\mathrm{Mg}$ and $\mathrm{SiO}$ grains at a few hundred degrees centigrade in space is also due to the characteristic behavior of nanometer-scale grains as illustrated by the behavior of the present $\mathrm{SiO}$ grains. Since dust formation in oxygen-rich stars is based on excess oxygen and the elements $\mathrm{Mg}, \mathrm{Fe}, \mathrm{Si}$ and $\mathrm{Al}$, the dynamic behavior of metallic clusters and oxide grains may also become important in the metamorphism of grains. If $\mathrm{SiO}_{x}$ grains exist in the excess oxygen gas at a few hundred degrees centigrade, then the grains may oxidize to $\mathrm{SiO}_{2}$ grains (Morioka et al. 1997). The direct alteration of these $\mathrm{SiO}_{2}$ and $\mathrm{SiO}_{x}$ grains due to their reaction with deposited metal clusters is now being studied experimentally. Some results may be reported in the near future.

\section{References}

Atou, Y., Suzuki, H., Kimura, Y. et al. 2003, Physica E, 16, 179 Dorschner, J., \& Henning, Th. 1995, A\&ARv, 6, 271

Henning, Th. 1997, Molecules in astrophysics - Probes and Processes, ed. E. F. van Dishoeck (Dordrecht Kluwer), 343

Kaito, C., \& Shimizu, T. 1984, Jpn J. Appl. Phys., 23, L7

Kaito, C. 1985, Jpn J. Appl. Phys., 24, 261

Kaito, C., \& Fujita, K. 1986, Jpn J. Appl. Phys., 25, 496

Kaito, C., Ojima, Y., Kamitsuji, K., et al. 2003, Meteor. Planet. Sci., 38,49

Kimura, S., Kaito, C., \& Wada, S. 2000, Antarct. Meteorite Res., 13, 145

Kimura, Y., Saito, Y., \& Kaito, C. 2003, Surf. Sci., 527, L219

Morioka, T., Kimura, S., Tsuda, N., et al. 1997, Antarct. Meteorite Res., 10, 449

Morioka, T., Kimura, S., Tsuda, N., et al. 1998, MNRAS, 299, 78

Mysen, B. O., \& Kushiro, I. 1988, Am. Mineralogist, 73, 1

Nagahara, H., Kushiro, I., \& Mysen, B. O. 1994, Geochim. Cosmochim. Acta, 58, 1951

Nuth, J. A., \& Donn, B. 1982, J. Chem. Phys., 77, 2639

Nuth, J. A. 1996, in The Cosmic Dust Connection, ed. J. M. Greenberg (The Netherlands: Kluwer Academic), 205

Phillips, H. R. 1971, J. Phys. Chem. Sol., 32, 1935

Rietmeijer, F. J. M., Nuth, J. A., \& Karner, J. M. 1999, AJ, 527, 395

Sandford, S. A. 1996, Meteor. Planet. Sci., 31, 449

Sosmamn, R. B. 1955, Trans. Brit. Cerm. Soc., 54, 657

Waters, L. B. F. M., Molster, F. J., de Jong, T., et al. 1996, A\&A, 315, L361 